\title{
Impact of Negative Pressure in a Room Due to Increased Airtightness in Residential Apartment Housing
}

\author{
Yoshihiro Toriumi ${ }^{1, *}$ and Takashi Kurabuchi ${ }^{2}$ \\ ${ }^{1}$ Tokyo Denki University, Ishizaka, Hatoyama, Hiki-gun, Saitama, Japan \\ ${ }^{2}$ Tokyo University of Science, 6-3-1 Niijyuku, Katsushika-ku, Tokyo, Japan
}

\begin{abstract}
This study surveyed the impact of a negative pressure in a room in a highly airtight residential apartment with Class 3 ventilation (natural air intake and mechanical exhaust). The results of the study are as follows. 1) A room may reach an excessive level of negative pressure depending on how the ventilation system is used. 2) Noise from the drain pipe of a room air conditioner caused by negative pressure in the room is dependent on how the drain pipe is installed. 3) An experiment was conducted to investigate the mechanism of a seal break in a toilet trap. However, the seal did not break. Thus, seal breaks may be caused by multiple factors.
\end{abstract}

\section{Introduction}

In the EU countries in order to spread the Nearly zeroenergy buildings of new construction or major refurbishment prior to 2020 , the building is mentioned about the need to high airtight and perform a ventilation correctly [1]. There are many discussions about the test conditions and test methods of the airtightness performance [2] [3], the construction guide for airtight buildings, and the advantages of building airtightness such as energy saving and zero carbon emission. On the other hand, the problems caused by building airtightness include the problem of indoor and outdoor pressure difference in high-rise buildings [4], and health problems caused by Indoor Air Quality (IAQ) such as moisture, carbon dioxide, mold, condensation, etc. [5]. Most of the IAQ problems can be corrected with the proper installation of a mechanical ventilation system. However, the problems caused by the installation of mechanical ventilation system in airtight buildings are hardly discussed.

Dwelling units in Japan are becoming increasingly airtight due to improvements in window sashes and construction techniques. Increased airtightness reduces the volume of draft and improves thermal comfort. It also enables preplanned mechanical ventilation. However, when the effective leakage area of an outdoor air inlet (denoted as $\mathrm{ELA}_{10}$ at $9.8 \mathrm{~Pa}$ ) is insufficient, the room pressure becomes significantly negative, causing difficulties in opening and closing the front door and windows, leading to noise in the drain pipe of room air conditioners, negatively impacting drainage traps, and compromising the drainage capacity of sanitary equipment.

Increased airtightness is significant, particularly in apartments. As discussed above, various problems have been recognized in residential facilities due to negative room pressure. However, a specific baseline value for negative pressure in a room and details on an outdoor air inlet have not been specified. Many other points are also unclear, such as those concerning noise in a drain pipe of a room air conditioner, and the mechanism of a seal break in a toilet trap.

This study investigates various problems caused by negative pressure in a room due to increased airtightness and its mechanical ventilation system [6]. Airtightness of the apartment, pressure difference between inside and outside the room, effective leakage area of the outdoor air inlet, and volume of air that passes through the ventilation system were measured. The mechanism that causes noise in a drain pipe of a room air conditioner was revealed. Fluctuation in the water level in a toilet trap and ideal pressure difference between inside and outside the room were also considered.

\section{Measurements taken for the study}

\subsection{Measured dwelling units}

Measurements were taken for this study at a 28-story-tall apartment complex called $\mathrm{E}$ with a central void. The building is located in the center of Tokyo and leasing started in 2007. Figure 1 shows dwelling unit E5. Dwellings are highly airtight as windows feature a double sash due to the fact that a train station is adjacent to the building. The outdoor air inlet has a soundproof hood on the outside, and the front door is a single door without an attached mailbox. A Class 3 general ventilation system (natural air intake and mechanical exhaust) is installed in the washroom, while one outdoor air inlet each is installed in the living room and the bed room. The range hood

* Corresponding author: toriumi@g.dendai.ac.jp 
supplies air naturally and exhausts air mechanically (concurrent supply and exhaust), and an electric shutter opens and close both the air inlet and outlet.

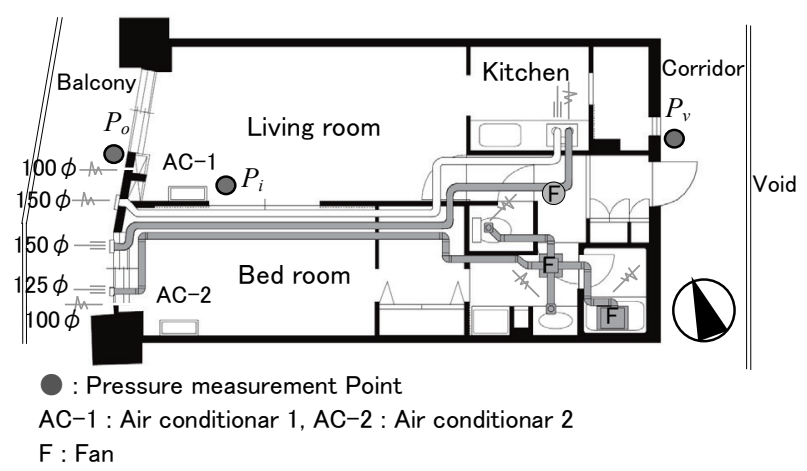

Fig. 1. Measured dwelling unit (E5).

\subsection{Dwellings Airtightness}

Airtightness was measured in three dwelling units with different floor plans (E3, E4, and E5) on the 15th floor. The results of the measurements are shown in Table 1. Measurements using pressurization method showed that the minimum, maximum, and average effective leakage area per floor area at $9.8 \mathrm{~Pa}\left(\mathrm{ELA}_{\mathrm{F} 10}\right)$ for a dwelling unit with a closed outdoor air inlet was $0.4 \mathrm{~cm}^{2} / \mathrm{m}^{2}$ (E5) at a minimum, $0.6 \mathrm{~cm}^{2} / \mathrm{m}^{2}(\mathrm{E} 4)$, and $0.5 \mathrm{~cm}^{2} / \mathrm{m}^{2}$, respectively. On the other hand, ELA $\mathrm{F}_{10}$ for dwelling units with an open outdoor air inlet $(\varphi=100 \mathrm{~mm})$ was $0.5 \mathrm{~cm}^{2} / \mathrm{m}^{2}$ for both E3 and E5, which showed a similar level of high airtightness.

Table 1. Airtightness measurements of dwelling units.

\begin{tabular}{l|c|c|c|c|c|c}
\hline Dwelling unit & \multicolumn{2}{|c|}{ E3 } & \multicolumn{2}{c|}{ E4 } & \multicolumn{2}{c}{ E5 } \\
\hline $\begin{array}{l}\text { Outdoor air } \\
\text { inlet }\end{array}$ & Closed & Open & Closed & Open & Closed & Open \\
\hline $\boldsymbol{n}$ & 0.79 & $\begin{array}{c}0.70 \\
(0.68)\end{array}$ & 0.65 & 0.63 & 0.79 & $\begin{array}{c}0.75 \\
(0.70)\end{array}$ \\
\hline $\mathbf{E L A}_{\mathbf{1 0}}\left[\mathbf{c m}^{2}\right]$ & 28.6 & $\begin{array}{c}49.0 \\
(34.5)\end{array}$ & 49.9 & 68.2 & 26.1 & $\begin{array}{c}39.1 \\
(31.1)\end{array}$ \\
\hline $\begin{array}{l}\mathbf{E L A} A_{\mathbf{F 1 0}} \\
{\left[\mathbf{c m}^{2} / \mathbf{m}^{2}\right]}\end{array}$ & 0.5 & $\begin{array}{c}0.8 \\
(0.5)\end{array}$ & 0.6 & 0.9 & 0.4 & $\begin{array}{c}0.6 \\
(0.5)\end{array}$ \\
\hline
\end{tabular}

Note $1 n$ is coefficient of leakage characteristics or exponent in the power law. $q=C(\Delta p)^{n}$. where, $q$ is measured air flow rate $\left[\mathrm{m}^{3} / \mathrm{h}\right]$, $C$ is coefficient of the power law $\left[\mathrm{m}^{3} /\left(\mathrm{h} \mathrm{Pa}^{\mathrm{n}}\right)\right]$ and $\Delta p$ is induced pressure difference $[\mathrm{Pa}]$.

Note 2 Numeric values in brackets are by depressurization method. Others are pressurization method.

Note $3 \mathrm{ELA}_{10}$ means specific effective leakage area. $q=(10000 / 3600) \cdot$ $\operatorname{ELA}_{10} \cdot(2 \Delta p / \rho)^{0.5}$. where, $\rho$ is air density $\left[\mathrm{kg} / \mathrm{m}^{3}\right]$ and $\mathrm{ELA}_{\mathrm{F} 10}=$ $\mathrm{ELA}_{10}$ / Floor area.

Table 2 shows some of the airtightness measurements taken in Japanese apartments. ELAF10 was approximately $8 \mathrm{~cm}^{2} / \mathrm{m}^{2}$ in the $1960 \mathrm{~s}$ and $5 \mathrm{~cm}^{2} / \mathrm{m}^{2}$ in the $1970 \mathrm{~s}$, showing an improvement of $3 \mathrm{~cm}^{2} / \mathrm{m}^{2}$ due to the openings retrofit Apartments have become increasingly airtight, reaching a value of $1 \mathrm{~cm}^{2} / \mathrm{m}^{2}$ by the turn of the century and falling to less than $0.5 \mathrm{~cm}^{2} / \mathrm{m}^{2}$ by approximately 2010 .
Table 2. Comparison of airtightness measurements (ELAF10) of apartment complex in Japan.

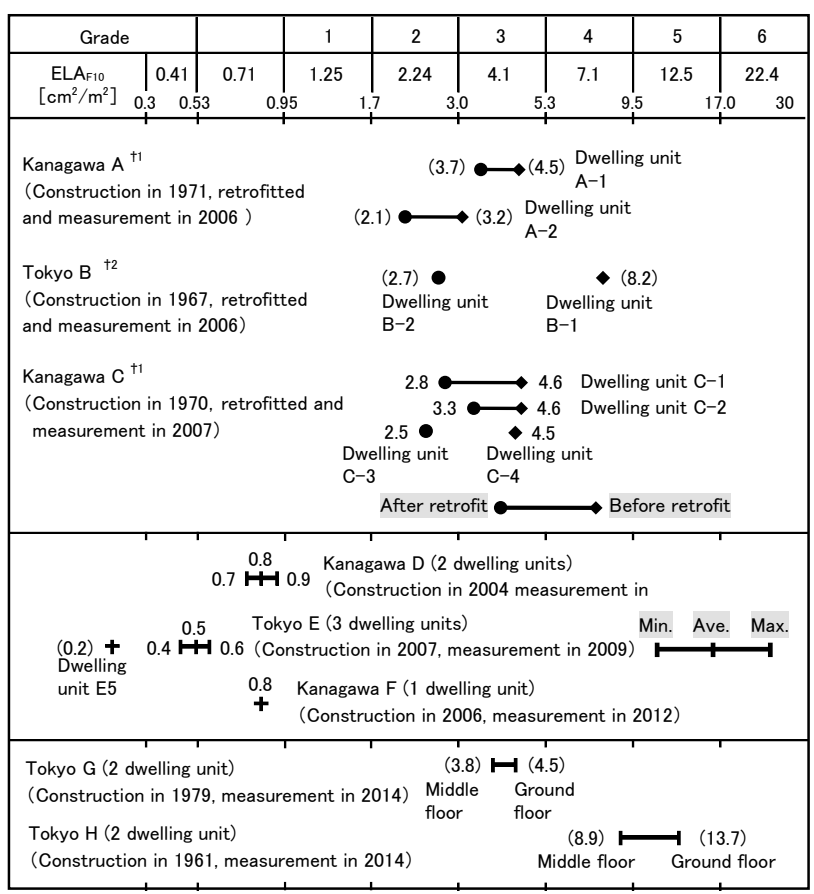

Note 1 Numeric values in brackets are by depressurization method. Others are pressurization method.

$\dagger 1$ Windows were retrofitted.

$\uparrow 2$ Windows and entrance door were retrofitted. (Steel window frames before retrofitting)

\subsection{Pressure difference between the inside and outside of a room}

Pressure difference between the inside and outside of a room (i.e., on the balcony), $p_{i}-p_{o}$, was measured for dwelling unit E5 (Figure 2). Six cases of operating status were considered for the ventilation system, which included "general ventilation only," "range hood only," and "general ventilation and range hood," one each for the open and closed outdoor air inlet. When the ventilation system operated as a general ventilation, the pressure was $47 \mathrm{~Pa}$ when the outdoor air inlet was open. The pressure nearly doubled to $85 \mathrm{~Pa}$ when the outdoor air inlet was closed. The results show the importance of the outdoor air inlet while the general ventilation system is in operation. On the other hand, when the range hood is operational, the negative pressure was small irrespective of whether the outdoor air inlet was open or closed. ELA $A_{10}$ for an outdoor air inlet of a range hood can be expected to be greater with respect to the outdoor air inlet ELA $\mathrm{E}_{10}$. The maximum negative pressure was $141 \mathrm{~Pa}$, which was observed for the cases in which the general ventilation (with the outdoor air inlet closed) and range hood (at its maximum capacity) were operational. Caution is advised for the summer and winter seasons when the outdoor air inlet tends to be closed. 


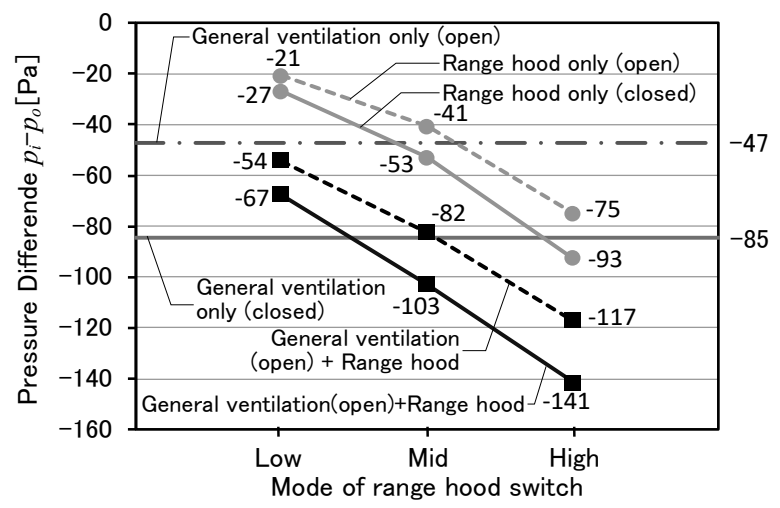

Fig. 2. Operating status of the ventilation system and pressure difference between the inside and outside of the room (E5). The brackets indicate the state of the outdoor air inlet.

\subsection{Opening force of the front door}

Many front doors open outwards, and the opening force of the front door can often pose a problem when the pressure within the room is negative. The allowable value for the opening force of a door alone is defined as $50 \mathrm{~N}$ for the JIS A 4702 Doorsets [7] and JIS A 4706 Windows [8]. On the other hand, the maximum physical strength required of a woman and a child to push and pull a door is assumed to be $98 \mathrm{~N}$ (10 kgf). Figure 3 shows the measurements taken for the opening force of the front door. While the force varies depending on the dimensions of the door parts and the door closer, the opening force of a front door is $50-80 \mathrm{~N}$ if the pressure difference between the inside and outside of the room is $50 \mathrm{~Pa}$.

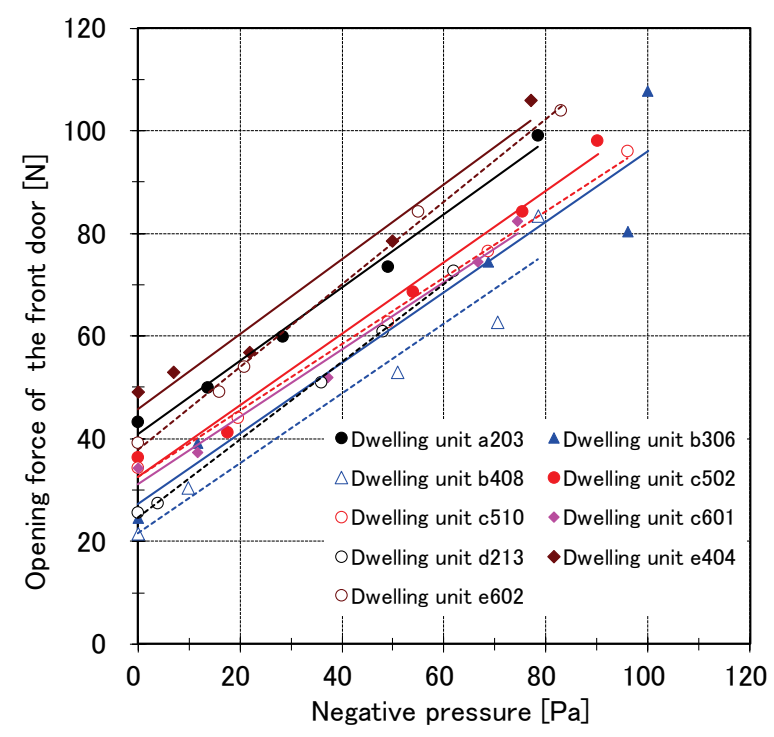

Fig. 3. Pressure difference between the inside and outside the room $\left(p_{o}-p_{i}\right)$, and the opening force of the front door.

\section{Experimental method}

\subsection{Noise from the drain pipe of a room air conditioner}

\subsubsection{Experiment on drain pipe noise}

Noise generated in a drain pipe of a room air conditioner (NC-60 at a distance of $1 \mathrm{~m}$ ) was verified for seven dwelling units in apartment E. First, a non-return valve (air-cut valve) installed on the drain pipe outside the room was removed. Next, to maximize the negative pressure in the room, the general ventilation system and range hood were operated concurrently with the outdoor air inlet closed. Finally, water was injected directly into the drain pipe or drain pan using an injector. At this time, the gradients of the room air conditioner itself and its drain pipe were measured.

Table 3 shows the results of the experiment. A noise was detected when the negative pressure was $20 \mathrm{~Pa}$. Noise was confirmed in over half of the room air conditioners. The common findings for dwellings in which a noise occurred were as follows: 1) a drain pipe has a reverse gradient, and 2) a installation position of the outdoor unit is on the balcony side. Noise also occurred when the drain pipe was parallel, but no noise was observed when the drain pipe had a downward slope. When the drain pipe is installed vertical to the floor, immediately adjacent to the body of the room air conditioner (left-hand side in Figure 4), a reverse draft is prevented in the drain pipe. On the other hand, when the drain pipe is long and laid out in a horizontal direction (right-hand side of Figure 4), the likelihood of the formation of a trap causing a noise increases. This is because the drain pipe is not fixed within the concealment cover, and a trap can form inside the cover, as shown on the right-hand side of Figure 4.

Table 3. Investigation of noise from the drain pipe of a room air conditioner

\begin{tabular}{c|c|c|c|c|c}
\hline $\begin{array}{c}\text { Dwelling } \\
\text { unit }\end{array}$ & Location $^{1}$ & Noise $^{2}$ & $\begin{array}{c}\text { Injection } \\
\text { volume } \\
{[\mathbf{m L}]}\end{array}$ & $\begin{array}{c}\text { Installation } \\
\text { position or the } \\
\text { outdoor unit }\end{array}$ & $\begin{array}{c}\text { Slope of } \\
\text { drain pipe }^{3}\end{array}$ \\
\hline \multirow{2}{*}{ E1 } & LD & & & balcony & Forward \\
\cline { 2 - 6 } & BR & & & Corridor & Forward \\
\hline \multirow{2}{*}{ E2 } & LD & + & 200 & balcony & 0.9 \\
\cline { 2 - 6 } & BR & & & Corridor & Forward \\
\hline \multirow{2}{*}{ E3 } & LD & & & balcony & N.A. \\
\cline { 2 - 6 } & BR & & & balcony & N.A. \\
\hline \multirow{2}{*}{ E4 } & LD & + & 340 & balcony & 1.7 \\
\cline { 2 - 6 } & BR & + & 110 & balcony & 12.5 \\
\hline \multirow{2}{*}{ E5 } & LD & + & 200 & balcony & 16.7 \\
\cline { 2 - 6 } & BR & + & 200 & balcony & 2.8 \\
\hline \multirow{2}{*}{ E6 } & LD & + & 200 & balcony & 13.9 \\
\cline { 2 - 6 } & BR & + & 60 & balcony & Level \\
\hline E7 & BR & & & Corridor & Forward \\
\hline
\end{tabular}

${ }_{1}^{1}$ LD: Refers living and dining room. ${ }^{2}+$ : Indicates noise generation.

3 Inverse gradient of the local part of the drain pipe.
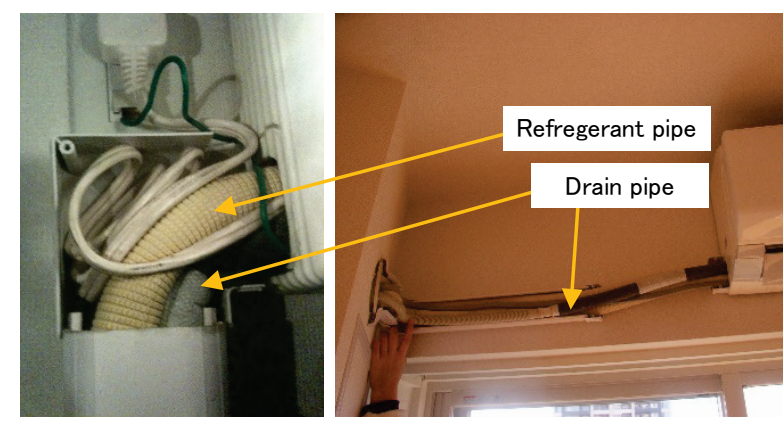

Fig. 4. Installation of a drain for a room air conditioner. 


\subsubsection{Mechanism causing the noise}

A clear vinyl tube was connected to the drain pipe outlet on the drain pan side to verify the movement of the drain water (Figure 5). Air from the outside flows in through the drain pipe (e.g. through the range hood) when the pressure in the room becomes significantly negative. At this time, if a trap is formed inside the drain pipe, a noise occurs as the drain vibrates due to the passage of the reflux airflow above the accumulated drain.

Measures for preventing such noise include the following: 1) installation of the drain pipe with a downward slope, and 2) use of a non-return valve. While installing the drain pipe vertically from the main body inside the room is also effective for Option 1), this is undesirable in terms of aesthetics and compromises the utility of the room. Option 2) requires maintenance, and in many cases, it also necessitates exchanging the valve; thus, the lifespan of the valve should be considered, because the valve is made of rubber in many cases.

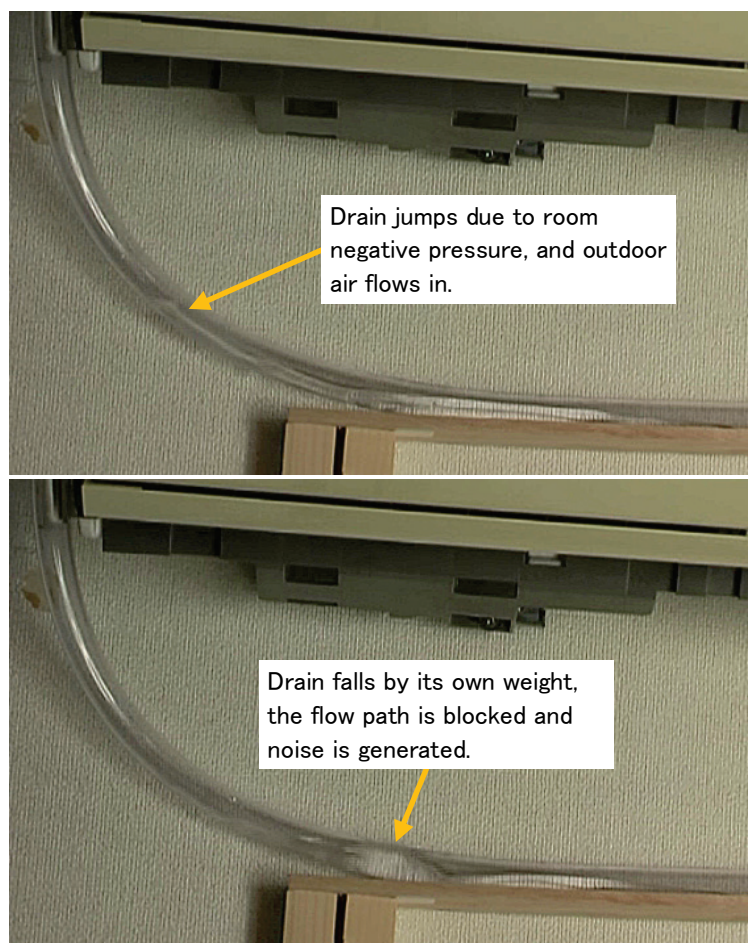

Fig. 5. Drain vibrating due to negative pressure in the room.

\subsection{Impact of seal of a toilet on water}

Several cases of seal breaks in the trap of the toilet bowl have been reported. Reduction in the water due to faulty in the seal in the toilet was investigated by measuring the fluctuation in pressure and the fluctuation in the reservoir in the toilet trap. While the pressure of the room is negative when the ventilation system is in operation, the pressure difference changes rapidly when a front door or windows is/are opened and the outside air flows in. Furthermore, wind from the outside affects not only the pressure difference but also the pressure inside the drainage pipe. Other factors such as the drainage load also contribute to the fluctuation in pressure inside a drainage pipe. The water level of the trap reservoir for a toilet is determined by the pressure difference between the room and drainage pipe, but for simplicity, the void pressure of the building was treated as the pipe pressure as its pressure fluctuation is small. The ventilation system was operated such that the pressure difference between the room and outside air on the void side $\left(p_{i}-p_{v}\right)$ was maximized. Every door inside the dwelling was opened, and the water level of the reservoir in the toilet was measured by changing the pressure by opening and closing the front door.

Figure 6 shows the fluctuation in the reservoir, and Figure 7 shows the measured results. The state of the surface of the reservoir when the ventilation system is turned off was defined as baseline (A). After turning the ventilation system on, the pressure in the room becomes negative, and the reservoir level rises (B). After flushing the toilet, the drainage pipe side of the trap is also filled with water, and the reservoir level rises further (C). Negative pressure in the room is mitigated once the door is opened, the reservoir level drops, and the water in the seal is reduced due to a self-siphoning effect (1). Keeping the door open for a while stabilizes the pressure difference (2), the pressure in the room becomes negative again, and the reservoir level rises when the door is closed again (3). Thereafter, the front door is repeatedly opened and closed $(1 \rightarrow 2 \rightarrow 3 \rightarrow 1 \ldots)$. Measurements were started after the door was opened and closed for the second time.

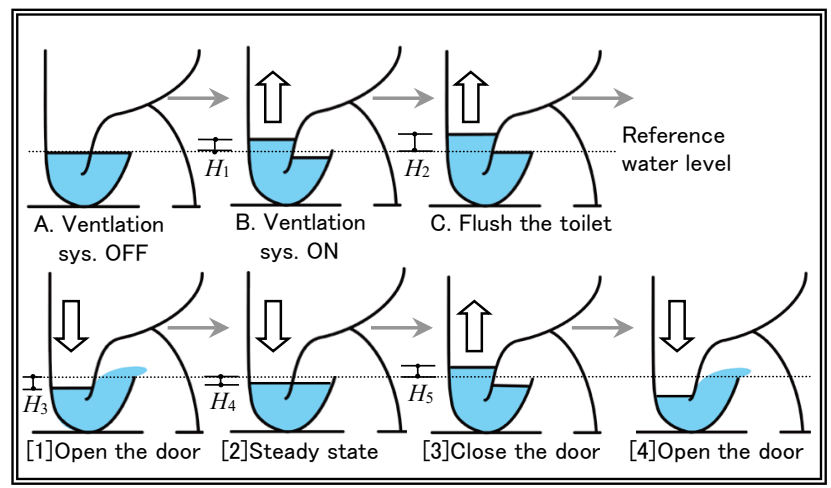

Fig. 6. Fluctuations in the water seal in a toilet bowl.

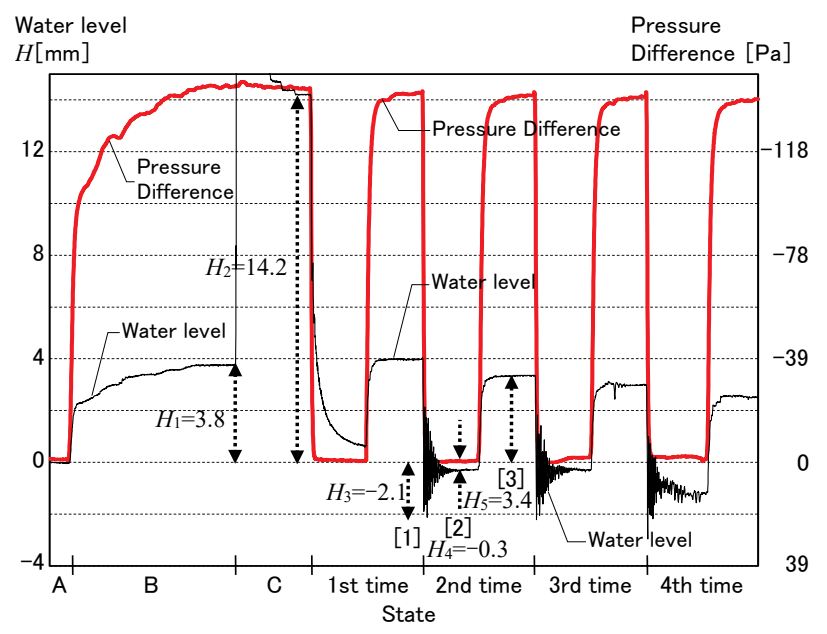

Fig. 7. Pressure difference $\left(p_{i}-p_{v}\right)$ and fluctuation in the water seal in a toilet. 
The apparent fluctuation in the reservoir level was $\mathrm{H}_{5}$ $\mathrm{H}_{3}=3.4-(-2.1)=5.5 \mathrm{~mm}$, which showed that the fluctuation in the water level of the reservoir was reduced. During the sixth door opening, the seal water level dropped by 2.0 mm compared to state A. As per the fluctuations of the reservoir level $\left(\mathrm{H}_{5}-\mathrm{H}_{4}\right)$, the pressure difference between the room and drainage pipe is assumed to be approximately $40 \mathrm{~Pa}$. However, the pressure difference between the room and void was much greater and measured to be approximately $140 \mathrm{~Pa}$. There were many uncertain elements, such as the drainage pipe pressure, which fluctuated due to the drainage load, and the Ratio of outflow cross section to inflow cross section of the trap. Therefore, estimating the pressure inside the drainage pipe using a fluctuation of the reservoir level is difficult. At the same time, this experiment did not result in the seal break phenomenon. A seal break in a toilet trap is thought to be caused by a combination of several factors in addition to negative pressure in the room, including the toilet usage pattern of the resident (e.g., overuse of toilet paper and the manner in which the handle for flushing is used), adoption of a water-conserving toilet, and external weather conditions, such as the wind outside the dwelling unit.

\section{Discussion}

\subsection{Effective leakage area and pressure difference inside and outside of the room}

The effective leakage area, $E L A_{\mathrm{pr}}$, at the reference pressure difference, $\Delta p_{\mathrm{r}}$, is calculated using equation 1 [6]:

$$
E L A_{\mathrm{pr}}=\frac{10000}{3600} C\left(\frac{\rho}{2}\right)^{0.5}\left(\Delta p_{\mathrm{r}}\right)^{n-0.5}
$$

where, $C$ is coefficient of leakage characteristics $\left[\mathrm{m}^{3} /(\mathrm{h} \mathrm{Pa})\right], \rho$ is air density $\left[\mathrm{kg} / \mathrm{m}^{3}\right]$ and $n$ is coefficient of leakage characteristics.

On the other hand, the air flow rate $q\left[\mathrm{~m}^{3} / \mathrm{h}\right]$ is determined using equation 2 :

$$
q=C(\Delta p)^{n}
$$

where, $\Delta p$ is pressure difference $[\mathrm{Pa}]$. Equation 1, the Equation 2 becomes Equation 3:

$$
\Delta p=\left[\frac{10000}{3600} \frac{q}{E L A_{p r}}\left(\frac{\rho}{2}\right)^{0.5}\left(\Delta p_{r}\right)^{n-0.5}\right]^{\frac{1}{n}}
$$

The pressure reference for this derived quantity is usually equal to $10 \mathrm{~Pa}$ in Japan. Equation 4:

$$
\Delta p=\left[\frac{10000}{3600} \frac{q}{E L A_{10}}\left(\frac{\rho}{2}\right)^{0.5}(9.8)^{n-0.5}\right]^{\frac{1}{n}}
$$

The equation does not take into account the impact of buoyancy due to the temperature difference between the inside and outside of the room. Nor does it consider natural ventilation by the outside air. Note that ELAF10 in the equation equals $E L A_{\mathrm{F} 10}$ for the entire dwelling unit, including the outdoor air inlet $E L A_{\mathrm{F} 10}$.

Assuming the air exchange rate is $N\left[\mathrm{~h}^{-1}\right]$, room volume is $V\left[\mathrm{~m}^{3}\right]$, floor area is $A_{\mathrm{F}}\left[\mathrm{m}^{2}\right]$, and ceiling height is $2.4 \mathrm{~m}$, yields equation 5 .

$$
q=N V=N\left(2.4 A_{\mathrm{F}}\right)=2.4 N A_{F}
$$

Substituting equation 5 into equation 4 yields equation 6.

$$
\Delta p=\left[\frac{10000}{3600} \frac{q}{E L A_{10} / A_{\mathrm{F}}}\left(\frac{\rho}{2}\right)^{0.5}(9.8)^{n-0.5}\right]^{\frac{1}{n}}
$$

$E L A_{10} / A_{\mathrm{F}}$ in equation 6 depicts $\mathrm{ELA}_{10}$ for the entire dwelling (dwelling unit + outdoor air inlet) divided by the floor area, which is assumed to be ELA $A_{F 10}$ for the entire dwelling. Figure 8 shows the relationship between ELAF10 for the entire dwelling unit and the pressure difference. Air density $\rho$ for the outside air is $1.2 \mathrm{~kg} / \mathrm{m}^{3}$ at a standard temperature of $20^{\circ} \mathrm{C}$, while the value for coefficient of leakage characteristics $C$ is assumed to be $2 / 3$. Similar results are obtained when a ventilating network calculation is performed for a single room. If the opening force of the front door is taken into account, the ideal pressure difference between the inside and outside of the room is approximately $50 \mathrm{~Pa}$ (Figure 3). As shown in Figure 8 , in order to keep the pressure difference within $50 \mathrm{~Pa}, E L A_{\mathrm{F} 10}$ for the entire dwelling unit should be at least $0.3 \mathrm{~cm}^{2} / \mathrm{m}^{2}$. In conservative terms, if $E L A_{\mathrm{F} 10}$ is at least $0.5 \mathrm{~cm}^{2} / \mathrm{m}^{2}$, the pressure difference will be within 50 $\mathrm{Pa}$ even when the air exchange rate reaches $0.75 \mathrm{~h}^{-1}$.

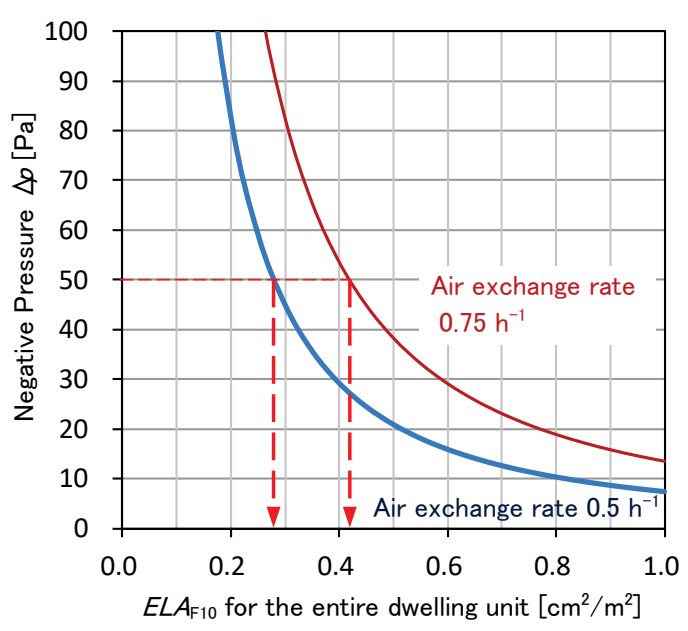

Fig. 8. Relationship between ELAf10 and pressure difference between the inside and outside of the room for the entire dwelling unit.

\section{Conclusions}

This study investigated the impact of negative pressure in rooms located within a highly airtight residential apartment building, where constant ventilation is assured by three types of installed ventilation systems. The following findings are reported. 
Pressure in a room can exceed -100 Pa depending on how the ventilation system and outdoor air inlet are used.

Noise from a drain pipe in an air conditioner caused by negative pressure in the room was observed in over half of the measured dwelling units. In dwelling units where a noise occurred, the study identified 1) a reverse draft in a drain pipe and 2) installation of the outdoor unit on the balcony side as common characteristics, and revealed that the noise depends on the construction of the drain pipe. With regard to the mechanism of the noise, the study also confirmed that a noise occurs when the drain vibrates due to the passage of a reflux airflow through the upper part of the drain when a trap is formed in the drain pipe.

With regard to the impact of negative pressure in a room on the seal water in a toilet, fluctuation in the reservoir level in the toilet trap was measured by opening and closing the front door, to vary the pressure difference inside and outside the room. The seal was not broken in this experiment, which suggests that a seal break is caused by several other overlapping factors in addition to the impact of negative pressure, including the toilet usage pattern of the resident, external weather conditions such as the external wind, and inhibited ventilation of the drainage pipe.

As per the results of a simple investigation, in which the allowable pressure difference was assumed to be 50 Pa from the opening force of the front door, $E L A_{\mathrm{F} 10}$ for the overall dwelling unit, including the outdoor air inlet, needs to be approximately $0.5 \mathrm{~cm}^{2} / \mathrm{m}^{2}$.

\section{References}

1. http://tightvent.eu/about

2. ASTM E779-10: Standard Test Method for Determining Air Leakage Rate by Fan Pressurization, ASTM International, 2010.1

3. ISO 12569: 2016(E): Thermal performance of buildings and materials - Determination of specific airflow rate in buildings - Tracer gas dilution method, 2016.6

4. Jae-Hun Jo et al., Characteristics of pressure distribution and solution to the problems caused by stack effect in high-rise residential buildings, Building and Environment, 42, Issue 1, 263-271, (Jan. 2007)

5. SG Howieson, T Sharpe, P Farren, Building tight ventilating right? How are new air tightness standards affecting indoor air quality in dwellings? , 35, Issue 5, 475-487, (Nov. 2013)

6. Y. Toriumi, T. Kurabuchi, M. Mizoguchi and S. Kodera, Effects of Building Envelope Airtightness with Mechanical Ventilation on Operation of Housing Equipment in Apartments, Transaction of the Society of Heating, Air-conditioning and Sanitary Engineerings of Japan, 43, 11-18(Nov. 2013)

7. JIS A 4702: Doorsets (2000)

8. JIS A 4706: Windows (2000) 